\title{
Evaluation of a Continuum Source Tungsten Coil Atomic Absorption Spectrometer: A Study of Zn Behavior
}

\author{
Joaquim A. Nóbrega ${ }^{*, a}$, Jennifer Rust ${ }^{b}$, Clifton P. Calloway, Jr. ${ }^{c}$ and Bradley T. Jones ${ }^{b}$ \\ ${ }^{a}$ Departamento de Química, Universidade Federal de São Carlos, CP 676, 13560-970 São Carlos - SP, Brazil \\ ${ }^{b}$ Department of Chemistry, Wake Forest University, Winston-Salem, NC 27109, USA \\ ${ }^{c}$ Department of Chemistry, Physics, and Geology, Winthrop University, Rock Hill, SC 29733, USA
}

O desempenho de um espectrômetro de absorção atômica com filamento de tungstênio, fonte contínua de deutério, monocromador Czerny-Turner e um detector de estado sólido foi avaliado para Zn. As principais características do instrumento são a simplicidade de operação e o custo relativamente baixo. Apesar do alto limite de detecção $\left(40 \mu \mathrm{g} \mathrm{L}^{-1}, 3\right.$ desvio padrão do branco/coeficiente angular), $\mathrm{Zn}$ foi determinado com exatidão em uma amostra de água e uma amostra de urina certificadas. A recuperação em água foi de $106 \%$ e em urina o resultado obtido está na região aceitável do certificado.

The performance of a tungsten coil atomizer atomic absorption spectrometer with a $\mathrm{D}_{2}$ lamp continuum source, a Czerny-Turner monochromator, and a charge coupled device detector was evaluated for the determination of $\mathrm{Zn}$. The main attractive characteristics of the instrument are its simplicity and the relative low cost of the atomizer. In spite of a poor limit of detection $\left(40 \mu \mathrm{g} \mathrm{L}^{-1}, 3\right.$ blank standard deviation/slope), $\mathrm{Zn}$ was accurately determined in one water and one urine certified reference standards. The recovery in water was $106 \%$ and in urine the obtained result is in the acceptable certified range.

Keywords: atomic absorption spectrometry, tungsten coil atomizer, continuum source, zinc

\section{Introduction}

Atomic absorption spectrometry (AAS) is well established as a powerful technique for measuring low concentrations of metals in different types of samples. The use of an electrothermal atomizer for generating the atomic cloud containing the analyte is frequently carried out using a graphite tube, but a tungsten coil could be a good alternative towards the development of a less expensive instrument. The feasibility of the tungsten coil atomizer has been investigated and its typical performance was recently discussed in two comprehensive review papers. ${ }^{1,2}$

The tungsten coil atomic absorption spectrometer (TCAAS) is characterized by the use of a low power supply for heating the atomizer. This aspect is related to both the low mass of the tungsten coil and the low specific heat of the tungsten metal when compared to graphite. Consequently, the atomizer does not require a cooling system for fast cooling down to room temperature after atomization. These outstanding characteristics make

*e-mail: djan@terra.com.br attractive the design of a portable device based on a tungsten coil furnace.

The development of this portable TCAAS could become still more attractive if combined to a continuum source lamp and a solid state detector. Such arrangement could open new routes for simultaneous determinations and investigations of interference processes.

The work here described dealt with a TCAAS built using a $\mathrm{D}_{2}$ lamp source, a Czerny-Turner monochromator, and a charge coupled device detector as part of an ongoing project to develop a simultaneous AAS.

In a recent review, it was discussed the use of a highresolution continuum source atomic absorption spectrometry based either in a flame or in a graphite furnace atomizer. ${ }^{3}$ In spite of a gradual trend towards the development of these powerful atomic absorption spectrometers, ${ }^{4,5}$ there are few publications dealing with TCAAS with simultaneous capability.

Ostrega et al. ${ }^{6}$ employed a two-channel atomic absorption instrument for simultaneous determination of $\mathrm{Cd}$ and $\mathrm{Pb}$ in water. Two more versatile approaches were proposed based on a beam combining optical arrangement ${ }^{7}$ 
or a multielement hollow cathode lamp. ${ }^{8}$ Both works used a charge coupled device detector and were used for determining $\mathrm{Cd}, \mathrm{Cu}$, and $\mathrm{Pb}$.

Zinc was chosen as the analyte to be tested since it allows the investigation of the performance of the instrument at a wavelength close to the vacuum ultraviolet where the sensitivity of the solid state detector can be degraded. Additionally, $\mathrm{Zn}$ is not an element frequently measured using TCAAS. There is no recent data about the behavior of this metal in this atomizer but the feasibility of its determination has already been demonstrated. ${ }^{9}$

\section{Experimental}

\section{Apparatus}

All measurements were carried out using a laboratoryconstructed continuum source TCAAS. A schematic diagram of the instrument is shown in Figure 1. The output from the $\mathrm{D}_{2}$ lamp (AIS model UV-2, Analytical Instrument Systems) was focused tangentially to the upper surface of the tungsten coil atomizer using a single fused silica lens, and the unabsorbed radiant flux exiting the opposite end of the furnace was imaged onto the entrance slit $(100 \mu \mathrm{m})$ of a $1.33 \mathrm{~m}$ focal length Czerny-Turner scanning monochromator (McPherson Model 209) using a second lens. The monochromator employed a 110 x $110 \mathrm{~cm} 3600$ grooves/mm grating. The monochromator wavelength was set to measure the $213.9 \mathrm{~nm}$ atomic line for $\mathrm{Zn}$, and the spectral window of the instrument arrangement allows measurements in a $4.8 \mathrm{~nm}$ range. The $100 \mu \mathrm{m}$ slit width provided a spectral bandpass of $0.02 \mathrm{~nm}$. The main limitation of the use of $\mathrm{a}_{2}$ lamp is that measurements are not feasible for wavelengths greater than $350 \mathrm{~nm}$. Investigations are in progress using a Xe arc lamp for overcoming this aspect when determining elements with analytical lines in the visible range.

The charge coupled device (CCD) detector ST133A and its controller SPEC-10, Princeton Instruments (Roper Scientific Trenton, NJ, USA) were used for measurements of the transient absorption signals. The temperature of the detector can be rapidly cooled-down and maintained at -
$40{ }^{\circ} \mathrm{C}$ by Peltier effect. This effect occurs when a current is passed through two dissimilar semiconductors (n-type and p-type) that are connected to each other at two junctions (Peltier junctions). The current drives a transfer of heat from one junction to the other. The Peltier effect can be exploited for cooling. ${ }^{10}$

The combination of the optical system and of the software for controlling the solid state detector offers the possibility of measuring all spectral environment near to the analyte, leading to a simple and fast correction of background signals by subtraction of the sample spectrum and a standard spectrum obtained for a matrix-matched standard without the analyte. It was not necessary to adopt this strategy here for $\mathrm{Zn}$ determination in water and urine.

The tungsten coil was from a commercial slide projector bulb (Osram, BRJ, 15 V, 150 W, Munich, Germany) and was positioned just below the radiation beam. A gaseous mixture composed of $90 \% \mathrm{Ar}+10 \% \mathrm{H}_{2}$ at a flow-rate of 1.0 $\mathrm{L} \min ^{-1}$ was used as the purge gas.

All reference solutions containing from 0.05 to $1.0 \mathrm{mg}$ $\mathrm{L}^{-1}$ were prepared by dilution of the $\mathrm{Zn}$ stock solution (1000 mg L ${ }^{-1}$, SPEX CertPrep, Metuchen, NJ, USA) in distilled-deionized water. Zinc was determined in a certified reference material containing trace metals in drinking water (High-Purity Standards, Charleston, SC, USA) and in a freeze-dried reconstituted urine (National Institute of Standards and Technology, NIST 2670, Gaithersburg, MD, USA).

\section{Procedure}

The tungsten coil was heated using the heating program shown in Table 1. The drying and pyrolysis steps were carried out in three successive applied voltages in the 3.0 to $3.5 \mathrm{~V}$ range. No losses of $\mathrm{Zn}$ were observed in this applied voltage range. The effect of the applied voltage during atomization on sensitivity was evaluated from 5.0 to 10.0 $\mathrm{V}$. All measurements were carried out by manually inserting $25 \mu \mathrm{L}$ of solution onto the tungsten coil with an Eppendorf pipetter.

The parameters set at the WinSpec-32 software were chosen for obtaining fast data acquisition. A total of 20

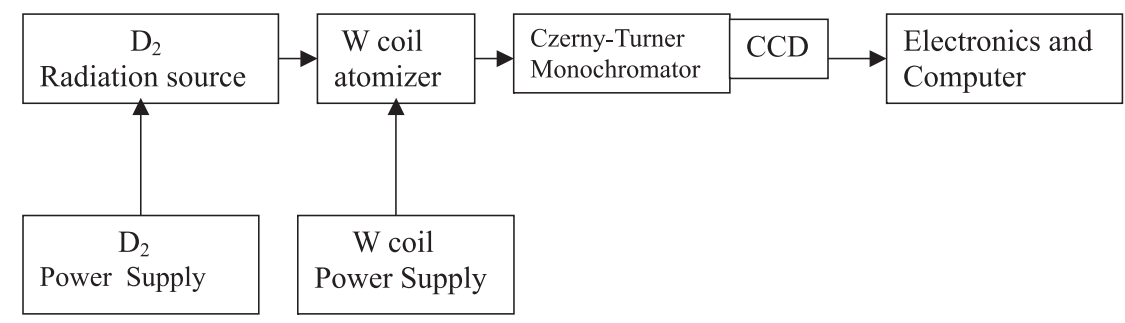

Figure 1. Instrument setup: tungsten coil atomizer. 
Table 1. Heating program for $\mathrm{Zn}$ atomization in the tungsten coil atomizer

\begin{tabular}{ccc}
\hline Applied Voltage $(\mathrm{V})$ & Time $(\mathrm{s})$ & Read \\
\hline 3.0 & 90 & No \\
3.2 & 60 & No \\
3.5 & 60 & No \\
0 & 10 & No \\
7.0 & 5 & Yes \\
\hline
\end{tabular}

spectra were successively measured with a time interval of $100 \mathrm{~ms}$ between each one of them. The detector was operated in full-speed mode, which means that all data are collected without any interruptions from the computer. The conversion speed was $1 \mathrm{MHz}$ for reaching the fastest possible data collection.

All measurements were performed by setting the detector temperature at $-40{ }^{\circ} \mathrm{C}$ for decreasing dark-charge effects on the baseline. All measurements of the $\mathrm{Zn}$ absorbance signals were carried out during the first $2 \mathrm{~s}$ of the atomization stage.

\section{Results and Discussion}

In addition to the capacity for measuring fast transient signals, the detector should be adjusted to avoid fast saturation of the pixels during the atomization stage. This aspect is dependent on the monochromator entrance slit size, the intensity of the $\mathrm{D}_{2}$ radiation beam at the $213.9 \mathrm{~nm}$ $\mathrm{Zn}$ wavelength, and on the position of the tungsten coil. Best signal-to-noise ratio conditions were set by using a $100 \mu \mathrm{m}$ slit and by positioning the tungsten coil just below the radiation beam and the entrance slit. These conditions led to signal saturation of the pixels only after $1.2 \mathrm{~s}$ of the beginning of the atomization stage when $7.0 \mathrm{~V}$ was applied for atomization and the $\mathrm{Zn}$ absorbance signal is measured before that. It should be mentioned that when $7.0 \mathrm{~V}$ was applied for atomization, the maximum signal for $\mathrm{Zn}$ was observed after $0.8 \mathrm{~s}$ of the onset of the atomization stage. The software shows all the variation of the transient signal during the formation and dissipation of the atomic cloud. Each measurement was taken in $100 \mathrm{~ms}$ interval (Figure 2). The use of a continuum source allows straightforward correction of the background absorption by measurements at both sides of the $\mathrm{Zn}$ analytical transient peak.

The atomization curve for $\mathrm{Zn}$ is shown in Figure 3. A sharp increase of the absorbance signal can be seen from 5.0 to $6.0 \mathrm{~V}$ and a plateau for applied powers higher than $7.0 \mathrm{~V}$. Further measurements were carried out by applying $7.0 \mathrm{~V}$ during the atomization stage.

The repeatability of the measurements was evaluated by 10 successive measurements of a solution containing

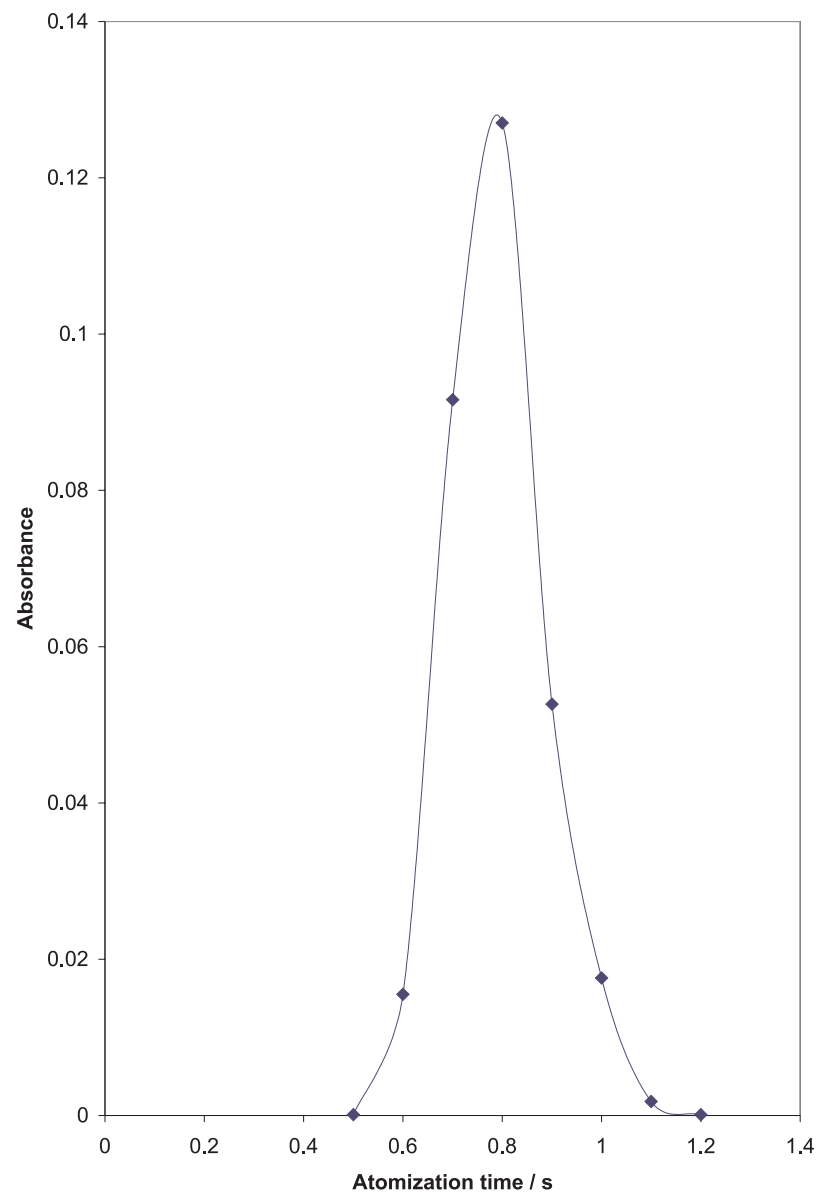

Figure 2. Atomization profile for $0.50 \mathrm{mg} \mathrm{L}^{-1} \mathrm{Zn}$.

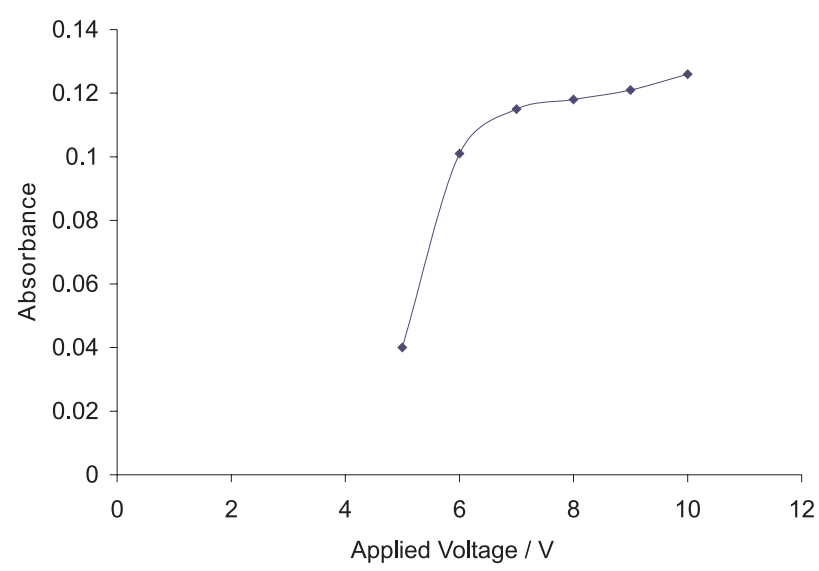

Figure 3. Atomization curve for a solution containing $0.50 \mathrm{mg} \mathrm{L}^{-1}$ $\mathrm{Zn}$.

$0.5 \mathrm{mg} \mathrm{L}^{-1} \mathrm{Zn}$. The relative standard deviation was 3.3\%. Ten successive measurements of the analytical blank led to a standard deviation of 0.0017 . It should be mentioned that the detector temperature and the choice of the pixels for measuring Io mainly affect the blank value. All measurements were carried out by keeping the detector 
temperature at $-40{ }^{\circ} \mathrm{C}$ and by measuring the same pixel at the right side of the $\mathrm{Zn}$ peak that occurred at the pixel 423. The limit of detection was estimated as $40 \mu \mathrm{g} \mathrm{L}^{-1}$. Compared to graphite furnace AAS (typical limit of detection $0.01 \mu \mathrm{g} \mathrm{L}^{-1}$ according to $\mathrm{Tsalev}^{11}$ ), this value reflects a poor limit of detection and it was mainly deteriorated by the measurements of the blank signal at only one pixel for a too fast transient signal. The TCAAS limit of detection for $\mathrm{Zn}$ could probably be improved by measuring the blank signals in various pixels around the analytical line and calculating a mean value.

Adopting the previous experimental conditions $\mathrm{Zn}$ was determined in a certified reference material containing trace metals in drinking water. The measured concentration was $74.3 \pm 12.1 \mu \mathrm{g} \mathrm{L}^{-1}(\mathrm{n}=4)$ and the certified concentration is $70 \mu \mathrm{g} \mathrm{L}^{-1}$. This certified material contains $6.0 \mathrm{mg} \mathrm{L}^{-1} \mathrm{Na}, 2.5$ $\mathrm{mg} \mathrm{L}^{-1} \mathrm{~K}, 35 \mathrm{mg} \mathrm{L}^{-1} \mathrm{Ca}$, and $9.0 \mathrm{mg} \mathrm{L}^{-1} \mathrm{Mg}$ as major elements. None of these elements seemed to interfere severely with the $\mathrm{Zn}$ determination and the sample was introduced onto the coil without any dilution or further treatment. The elevated relative standard deviation observed (16.3\%) could probably be related to kinetic effects caused by concomitants on the formation of the fast transient signal. However, the accuracy was not negatively affected. It should also be mentioned that all values were based on peak height measurements at the pixel with maximum signal. A complete study of interference effects is beyond the goal of the developed work.

Preliminary results also indicated that $\mathrm{Zn}$ can be accurately determined in a freeze-dried reconstituted urine (NIST 2670). This element is not certified due to contamination from the stopper used in the packaging, but it is mentioned that the concentration varied from 0.5 to $1.5 \mathrm{mg} \mathrm{L}^{-1}$ in reconstituted samples. Our results indicated a $0.68 \pm 0.06 \mathrm{mg} \mathrm{L}^{-1}(\mathrm{n}=3)$ in reconstituted urine diluted 4-fold. The only parameter changed to make this measurement was the duration of the second pyrolysis stage that was extended to $140 \mathrm{~s}$. This long pyrolysis stage at $3.2 \mathrm{~V}$ was operative for decreasing background signal and no background correction was performed for a urine sample diluted 4-fold. Results obtained by graphite furnace AAS confirmed the determined value.

\section{Conclusions}

It was demonstrated that the TCAAS with $\mathrm{D}_{2}$ lamp continuum source and a CCD detector can be applied for the determination of $\mathrm{Zn}$ in water and urine. Other elements with analytical lines in the ultraviolet region could be determined using this same setup and the only required modification is the position of the diffraction grating of the Czerny-Turner monochromator. The TCAAS instrument presents capacity for portability, it is relatively low cost and a technician without extensive training can operate it. All these characteristics make it attractive as a fast screening purpose instrument.

\section{Acknowledgements}

This material is based upon work supported by the National Science Foundation and the Intelligence Technology Innovation Center through the joint "Approaches to Combat Terrorism" Program Solicitation NSF 03-569 (CHE-0346353). J.A.N. is thankful to Departamento de Química, Universidade Federal de São Carlos by his one-semester license and to the Coordenação de Aperfeiçoamento de Pessoal de Nível Superior (CAPES) for support (Process 0808-03-2).

\section{References}

1. Ribeiro, A.S.; Arruda, M.A.Z.; Cadore, S.; Quim. Nova 2002, $25,396$.

2. Hou, X.; Jones, B.T.; Spectrochim. Acta 2002, 57B, 659.

3. Welz, B.; Becker-Ross, H.; Florek, S.; Heitmann, U.; Vale, M.G.R.; J. Braz. Chem. Soc. 2003, 14, 220.

4. Harnly, J.M.; J. Anal. At. Spectrom. 1999, 14, 137.

5. Becker-Ross, H.; Florek, S.; Heitmann, U.; J. Anal. At. Spectrom. 2000, 15, 137.

6. Ostrega, P.; Bulska, E.; Hulanicki, A.; Chem. Anal. 1993, 39, 779.

7. Wagner, K.A.; Levine, K.E.; Jones, B.T.; Spectrochim. Acta 1998, 53B, 1507.

8. Salido, A.; Jones, B.T.; Talanta 1999, 50, 649.

9. West, M.H.; Molina, J.F.; Yuan, C.L.; Davis, D.G.; Chauvin, J.V.; Anal. Chem. 1979, 51, 2370.

10. www.uni.konstanz.de/physic/Jaeckle/papers/thermopower, accessed at October 27, 2004.

11. Tsalev, D.L.; Atomic Absorption Spectrometry in Occupational and Environmental Health Practice, Vol. III, CRC Press: Boca Raton, 1995.

Received: March 2, 2004

Published on the web: March 9, 2005

FAPESP helped in meeting the publication costs of this article. 